Original Contribution

\title{
SEXUAL DIMORPHISM IN BODY PARAMETERS OF THE GOLDEN JACKAL CANIS AUREUS L., 1758 (CARNIVORA, CANIDAE) IN THE SARNENA SREDNA GORA MOUNTAIN AND THRACIAN PLAIN (BULGARIA)
}

\author{
E. Raichev ${ }^{1 *}$, S. Peeva ${ }^{1}$, R. Masuda ${ }^{2}$, Y. Kaneko ${ }^{3}$, H. Tsunoda ${ }^{4}$, Dian Georgiev $^{5}$, \\ Dilian Georgiev ${ }^{6}$ \\ ${ }^{1}$ Department of Animal Production - Non-ruminants and Other Animals, Faculty of Agriculture, \\ Trakia University, Stara Zagora, Bulgaria \\ ${ }^{2}$ Department of Biological Sciences, Faculty of Science, Hokkaido University, Sapporo, Japan \\ ${ }^{3}$ Carnivore Ecology and Conservation Research Group, Institute of Agriculture, Tokyo University of \\ Agriculture and Technology, Saiwaicho, Fuchu-city, Tokyo, Japan \\ ${ }^{4}$ Center for Environmental Science in Saitama, Kamitanadare, Kazo-shi, Saitama, Japan \\ ${ }^{5}$ Department of Biology and Aquaculture, Faculty of Agriculture, Trakia University, Stara Zagora, \\ Bulgaria \\ ${ }^{6}$ Department of Ecology and Environmental Protection, Plovdiv University "Paisiy Hilendarski", \\ Plovdiv, Bulgaria
}

\begin{abstract}
The study was conducted in the area of the Sarnena Sredna Gora Mountain and the Thracian Plain in period 1996-2014. On a total of 262 golden jackals (Canis aureus L., 1758) (119 males and 143 females) thirteen somatometric parameters were measured. The comparison of the linear body parameters and the weights between males and females showed apparent sexual dimorphism in the jackals with a high level of reliability, with an exception of the length of the tail. The index of body compactness and the weight index were calculated and compared. The index of body compactness did not differ between sexes. The body weight $(10,994.24 \mathrm{~g}$ for males and 9,776.02 $\mathrm{g}$ for females in average) showed clear sexual dimorphism - male-female ratio was $11.08 \%$. Our findings indicated that the sexual size dimorphism in golden jackal was weaker and lower than those in red fox and wolf.
\end{abstract}

Key words: body mass, circumference, linear parameters, weight index

\section{INTRODUCTION}

Sexual dimorphism in body size and mass is clearly widespread among mammalian taxa, with male-biased dimorphism being the more common, but certainly not exclusive pattern (1). Male-biased dimorphism relates to sexual selection on males through male-male competition for females. Selection pressure on female mass, identified in that age at weaning is higher in polygynous species. However, the reproductive rate is lower for larger females, indicating that fecundity selection selects smaller females (2).

\footnotetext{
*Correspondence to: Ev geniy Raichev, Department of Animal Production - Non-ruminants and Other Animals, Faculty of Agriculture, Trakia University, Stara Zagora, 6000, Bulgaria, eraichev@uni-sz.bg
}

In species which males are larger than females, previous studies often find that sexual dimorphism increases with increasing body size (3). Sexual size dimorphism can be the result of a number of combined factors and (4) have suggested that these influences should be examined on a taxon-by-taxon basis. The bioenergetics hypothesis in which a female in first year pregnancy has reproductive advantage to divert "growth resources" to the developing fetuses, is accounted for sexual dimorphism for coyotes, Canis latrans Say, 1823, Canidae (5).

Sexual size dimorphism, with males being larger than females is well documented for some canids: coyotes $(6,7,8)$; red foxes, Vulpes vulpes Linnaeus, 1758 (9, 10); wolves, 
C. lupus Linnaeus, $1758(11,12)$; and domestic dogs (13).

Socially monogamous species as $C$. aureus are only weakly dimorphic in skeletal shape and body mass. This feature improves male aggressive performance for limiting copulations by individuals excepting reproductive pairs through behaviours such as mate-guarding or direct control of conspecific competitors or packmates (14).

The golden jackal, C. aureus Linnaeus, 1758, is distributed mainly in the Southeast and South Asia and East Africa (15). Its range of distribution comprises the Balkan Peninsula, as well (16). This species has begun its spread from the Balkan Peninsula to Central and Western Europe since the 1980s till now (17). The largest and the most stable population in this region is in Bulgaria.

There are few studies on the morphology of the species in the Balkan Peninsula (18), while male-biased sexual dimorphism in cranium of jackals in Bulgaria was found by (19).

In this study we analyzed morphological characters on 262 sampled golden jackals from Bulgaria, and discuss occurrence of the apparent sexual dimorphism.

\section{MATERIALS AND METHODS}

\section{Study area and sample collections}

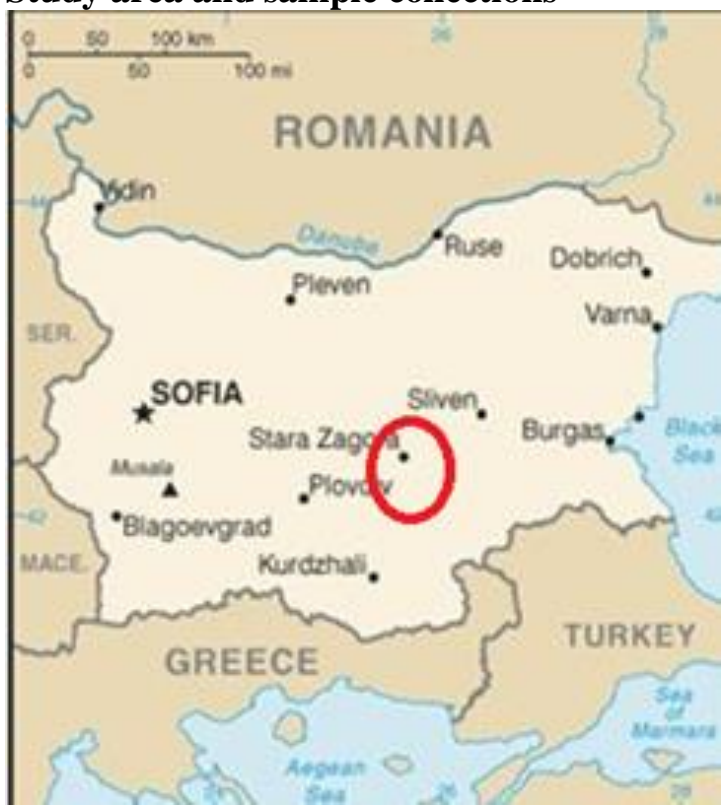

Figure 1. Location of the study area in Bulgaria, shown by circle

Figure 1 shows the location of the study area which covers the Sarnena Sredna Gora Mountain and part of the Thracian Plain. In Sredna Gora woodlands dominate alternating with arable lands. The study area is located near the city of Stara Zagora $\left(42^{\circ} 24-34^{\prime} \mathrm{N}\right.$, $\left.25^{\circ} 16-56^{\prime} \mathrm{E}\right)$. The terrain is mostly hilly at an altitude of 350-1236 m. Settlements are spaced at $3-5 \mathrm{~km}$ from one another. The Upper Thracian Plain (up to $400 \mathrm{~m}$ a.s.1.) is the largest plain in Bulgaria. It includes the Stara Zagora field (20). The level of urbanization is the same, but arable land dominates, compared to Sredna Gora Mountain. The climate is relatively mild, and according to the KoppenGeiger Climate Classification the code is Dfb (21).

We used the carcasses of 262 jackals, of which 119 males and 143 females, all at an age above 9 months. The samples were collected during the winter (December, January and February) between 2006 and 2014. The animals were shot by hunters and foresters in organized and individual hunting for predators in order to reduce their numbers in the game rearing areas near Stara Zagora (Figure 1). After deworming carcasses were measured in the Taxidermy laboratory at the Faculty of Agriculture at Trakia University.

\section{Measurements and calculations}

A total of 12 linear parameters of the external morphology and the carcass weight of cadaveric material were taken:

- Total body length from the tip of snout to the tip of tail along the backline (TBL)

- Total body length from the tip of the snout to the tip of the tail sideways of the body (TBL-s)

- Body length from the tip of the snout to the base of the tail along the backline (BL)

- Body length from the tip of the snout to the buttock (sideways of the body) straight body length (BL-s)

- $\quad$ Length of the tail with hair (LTh)

- Length of the tail to the last sacral vertebra (LT)

- Fore limb length from the withers to the ulnar tuberosity (FLL- 1)

- Length of fore limb from the elbow to the nail tips (FLL- 2)

- $\quad$ Length of hind limb from the knee joint to the nail tips (HLL)

- Circumference of breast immediately behind the front limb (CB)

- $\quad$ Circumference of the metacarpus $(\mathrm{CMc})$

- $\quad$ Circumference of the metatarsus (CMt)

- $\quad$ Carcass weight $(\mathrm{CW})$

For linear measurements carcasses were placed on a horizontal surface in the position shown in Figure 2. The specified linear parameters were measured using a flexible measuring tape to the nearest $0.5 \mathrm{~cm}$. The weight was measured with an electronic scale accurate up to $5 \mathrm{~g}$. 


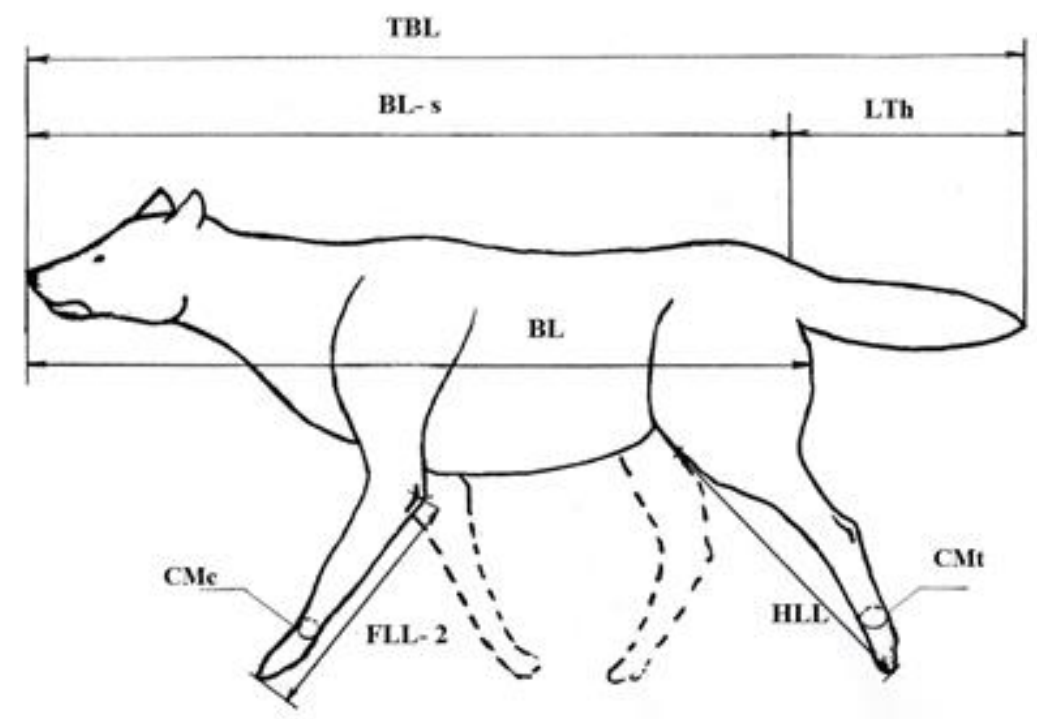

Figure 2. Morphological parameters in the exterior of the golden jackal measured in this study

We calculated two indices: 1) weight index, CW/BL and CW/BL-s; 2) compactness index, $\mathrm{CB} / \mathrm{BL}$ and $\mathrm{CB} / \mathrm{BL}-\mathrm{s}$. Sexual dimorphism was assessed in two ways as: 1) a ratio of the value of the parameter of the male animal to that of female (22); and 2) dimorphism rate, calculated as a ratio of the difference between the measurements divided by the larger measurement (in \%) (10).

The data on the variability of the characteristics and the level of statistically significance (t-test) of the differences between sexes were processed with STATISTICA 6.0 software (StatSoft Inc., 2002).

\section{RESULTS AND DISCUSSION}

Three of the parameters were more variable than others, both in males (LTh- Vc=7.75, LT$\mathrm{Vc}=8.09$, CB- $\mathrm{Vc}=7.70$; Table 1) and females $(\mathrm{Vc}=7.45 ; \quad \mathrm{V} c=7.91 ; \quad \mathrm{Vc}=8.10 ; \quad$ Table 2), respectively. The high variability in terms of the tail length is attributed to possible individual differences. The variation in the circumference of the breast could be due both to individual characteristics and the different degrees of obesity of the individuals during sampling. Other linear parameters varied at a lesser extent: $\mathrm{Vc}=4.22-5.92$ for males (Table 1) and $V_{c}=3.68-6.04$ for females (Table 2).

The weights of males averaged $10,994 \mathrm{~g}(\mathrm{SD}=$ $1,597.33$ ) and ranged from 6,650 to $14,500 \mathrm{~g}$, whereas those of females were 9,776 $\mathrm{g}(\mathrm{SD}=$ $1,480.60$ ), ranged from 4,900 to $13,620 \mathrm{~g}$, and lower than males. The body weight had higher coefficient of variation than any linear parameters (males, $\mathrm{Vc}=14.53$ and females, $\mathrm{Vc}$ =15.15; Tables 1 and 2). This could be due to the different level of obesity of the sampled specimens.

Table 1. Mean values and degrees of variability of the parameters of body length and mass in male jackals collected in central Bulgaria

\begin{tabular}{ccccccc}
\hline Parameter & $\mathrm{n}$ & Mean & Minimum & Maximum & Std.Dev. & Vc \\
\hline TBL & 118 & 113.09 & 101.00 & 124.00 & 4.94 & 4.37 \\
TBL- s & 118 & 110.69 & 99.00 & 121.00 & 4.67 & 4.22 \\
BL & 119 & 82.74 & 73.00 & 92.00 & 3.55 & 4.29 \\
BL- s & 119 & 80.25 & 70.00 & 90.00 & 3.47 & 4.32 \\
LTh & 118 & 31.36 & 20.00 & 37.00 & 2.43 & 7.75 \\
LT & 118 & 23.24 & 13.00 & 28.00 & 1.88 & 8.09 \\
FLL- 1 & 105 & 22.83 & 20.00 & 26.00 & 1.33 & 5.81 \\
FLL- 2 & 107 & 27.81 & 20.00 & 30.00 & 1.60 & 5.76 \\
HLL & 107 & 30.87 & 27.00 & 35.00 & 1.40 & 4.54 \\
CB & 118 & 57.53 & 47.00 & 67.00 & 4.43 & 7.70 \\
CMc & 107 & 9.28 & 8.00 & 10.50 & 0.55 & 5.92 \\
CMt & 107 & 8.88 & 7.50 & 10.20 & 0.52 & 5.84 \\
CW & 116 & 10994.24 & 6650.00 & 14500.00 & 1597.33 & 14.53 \\
\hline
\end{tabular}

Units of parameters are centimeters, except for CW (grams) 
RAICHEV E., et al.

Table 2. Mean values and degrees of deviation of the parameters of body length and mass in female jackals collected in central Bulgaria

\begin{tabular}{ccccccc}
\hline Parameter & $\mathrm{n}$ & Mean & Minimum & Maximum & Std.Dev. & Vc \\
\hline TBL & 140 & 109.73 & 99.000 & 124.00 & 4.38 & 3.99 \\
TBL- s & 140 & 107.35 & 97.00 & 117.00 & 3.95 & 3.68 \\
BL & 140 & 80.16 & 72.00 & 88.00 & 3.24 & 4.04 \\
BL- s & 140 & 77.40 & 69.00 & 85.00 & 3.08 & 3.98 \\
LTh & 140 & 30.69 & 25.00 & 38.00 & 2.29 & 7.45 \\
LT & 139 & 22.79 & 16.00 & 27.00 & 1.80 & 7.91 \\
FLL- 1 & 125 & 22,02 & 18,00 & 28,00 & 1,33 & 6,04 \\
FLL- 2 & 125 & 26.76 & 24.00 & 30.50 & 1.17 & 4.35 \\
HLL & 125 & 29.45 & 26.50 & 33.00 & 1.30 & 4.43 \\
CB & 139 & 54.79 & 42.00 & 64.00 & 4.44 & 8.10 \\
CMc & 125 & 8.83 & 7.80 & 9.80 & 0.51 & 5.81 \\
CMt & 125 & 8.48 & 7.50 & 9.80 & 0.48 & 5.61 \\
CW & 133 & 9776.02 & 4900.00 & 13620.00 & 1480.60 & 15.15 \\
\hline
\end{tabular}

Units of parameters are centimeters, except for CW (grams)

Male animals demonstrated definitely higher values (2.97- $4.85 \%)$ of the basic linear parameters: TBL, BL, BL-s, HLL and FLL-2, CB,CMs and CMt $(\mathrm{p} \leq 0.001)$ (Table 3). Tail length regardless of the method of measurement showed low level of significant for LTh $(\mathrm{p} \leq 0.05)$ or insignificant for LT $(\mathrm{p} \geq$
0.05). These parameters depended on the sex to a lesser extent. Probably individual differences were predominant. Sexual size dimorphism was proved in the weight of animal; males are heavier than females $(11.08 \%)$.

Table 3. Sexual dimorphism on the sizes of the golden jackal, expressed as the ratios and percentages of the measured parameters

\begin{tabular}{|c|c|c|c|}
\hline Parameter & $\mathrm{p}$ & $\begin{array}{l}\text { male/female } \\
\text { ratio }\end{array}$ & $\begin{array}{c}\text { dimorphism rate } \\
(\%)\end{array}$ \\
\hline TBL, cm & $\mathrm{p} \leq 0.001$ & 1.03 & 2.97 \\
\hline TBL- s, cm & $\mathrm{p} \leq 0.001$ & 1.03 & 3.01 \\
\hline BL, cm & $\mathrm{p} \leq 0.001$ & 1.03 & 3.12 \\
\hline BL- s, cm & $\mathrm{p} \leq 0.001$ & 1.04 & 3.55 \\
\hline LTh, cm & $\mathrm{p} \leq 0.05$ & 1.02 & 2.14 \\
\hline $\mathbf{L T}, \mathbf{c m}$ & $\mathrm{p} \geq 0.05$ & 1.02 & 1.94 \\
\hline FLL- 1, cm & $\mathrm{p} \leq 0.001$ & 1.04 & 3.55 \\
\hline FLL- 2, cm & $\mathrm{p} \leq 0.001$ & 1.04 & 3.78 \\
\hline HLL, cm & $\mathrm{p} \leq 0.001$ & 1.15 & 4.60 \\
\hline $\mathrm{CB}, \mathrm{cm}$ & $\mathrm{p} \leq 0.001$ & 1.05 & 4.76 \\
\hline CMc, $\mathbf{c m}$ & $\mathrm{p} \leq 0.001$ & 1.05 & 4.85 \\
\hline CMt, cm & $\mathrm{p} \leq 0.001$ & 1.04 & 4.50 \\
\hline $\mathbf{C W}, \mathrm{g}$ & $\mathrm{p} \leq 0.001$ & 1.12 & 11.08 \\
\hline CW/BL & $\mathrm{p} \leq 0.001$ & 1.09 & 8.30 \\
\hline CW/BL- $s$ & $\mathrm{p} \leq 0.001$ & 1.08 & 7.90 \\
\hline CB/BL (\%) & $\mathrm{p} \geq 0.05$ & 1.02 & 1.67 \\
\hline CB/BL- s (\%) & $\mathrm{p} \geq 0.05$ & 1.01 & 1.26 \\
\hline
\end{tabular}

There were statistically significant differences in two weight indices $(8.3 \%$ and $7.9 \%$, $\mathrm{p} \leq 0.001$ for each; Table 3), while no significant differences in the compactness index $(1.67 \%$ and $1.26 \%, \mathrm{p} \geq 0.05$ for each; Table 3). This might result from the differences in the body conditions of the sampled animals. The body mass is the most dimorphic feature in our study. There are several studies concerning body mass of wild canids: for example, male body masses in wolves are $18 \%$ heavier than those of females in Canada (12); and, in Bristol, United
Kingdom, males of red foxes are $15.6 \%$ heavier than females on average (9). Our data shows that sexual size dimorphism in golden jackal is lower than these two canids, and males were about 1.12 times heavier than females (Table 3). Contrary to the results of the present study, (23) didn't find any sexual dimorphism in body mass and body length in Middle Caucasian golden jackals. (24) reported that the golden jackal in Caucasus showed marked geographic differences for sexual dimorphism and, these differences were stronger than those in foxes and wolves. A 
number of studies have linked sexual dimorphism with latitude and climatic variations (e.g., 25, 26).

Because of the widespread distribution with various latitudes and climatic zones, we suggested geographical differences in sexual dimorphism in golden jackals.

\section{CONCLUSIONS}

- According to the linear parameters of the body, there was sexual size dimorphism in the golden jackal in Central Bulgaria; the males had larger bodies than the females. That fact was also evidenced by the differences in the body weight index.

- The compactness index and the tail length in the golden jackal in Central Bulgaria did not depend on sex.

- The sexual size dimorphism in golden jackal was weaker and lower than that in red fox or wolf.

- More data from different parts of distribution area of golden jackal for defining the level of geographic variations in sexual dimorphism are needed.

\section{ACKNOWLEDGEMENTS}

The collaboration of hunters, game wardens and stuff of local branch of Forestry Agency is gratefully acknowledged. This work was partly supported by Grants-in-Aid for Scientific Research (Nos. 22405003 and 26257404) from the Japan Society for the Promotion of Science.

\section{REFERENCES}

1. Isaac, J., Potential causes and life-history consequences of sexual size dimorphism in mammals. Mammal review, Vol. 35 (1): 101-115, 2005.

2. Lindenfors, P., Gittleman, J., Jones, K., Sexual size dimorphism in mammals in: Fairbairn, D., Blanckenhorn, W., \& Szekely, T., Sex, Size and Gender Roles: Evolutionary Studies of Sexual Size Dimorphism, Oxford University Press, New York, pp. 280, 2007.

3. Rensch, B., Evolution above the species level xvii., Methuen \& Co. Ltd, London, 419 p., 1959.

4. Karubian, J. and Swaddle, J., Selection on females can create "larger males". Proceedings of the Royal Society Series BBiological Sciences, 268, 725-728, 2001.

5. Blood, B., Matson, J., Pattern, D., Multivariate analysis of algometry in a single population of coyotes (Canidae: Canis latrans Say). Australian Mammalogy, 8: 221-231, 1985.
6. Bekoff, M., Canis latrans. Mammalian Species. 79:1-9, 1977.

7. Kennedy, M., Mech, S., Tran, B., Grubaugh, J., Lance, R., An assessment of geographic variation in sexual size dimorphism in the coyote (Canis latrans). Mammalia 67(3): 411-418, 2003.

8. Lydeard, C. and Kennedy, M., Morphologic Assessment of Recently Founded Populations of the Coyote (Canis latrans) in Tennessee. Journal of Mammalogy, Vol. 69 (4) pp. 773-781, 1988.

9. Iossa, G., Sonlsbury, C., Baker, Ph., Harris, St., Body Mass, Territory Size, and LifeHistory Tactics in a Socially Monogamous Canid the Red Fox Vulpes vulpes. Journal of Mammalogy, Vol. 89 (6) pp. 1481-1490, 2008.

10.Cavallini, P., Variation in the body size of the red fox. Annales Zoologici Fennici, 32: 421-427, 1995.

11.Trobojevic, I. and Cirovic, D., Sexual dimorphism and population differentiation of the wolf (Canis lupus) based on morphometry in the Central Balkans. North-Western Journal of Zoology (Online first): art. 151709 (in press), 2015.

12.Hillis, T. and Mallory, F., Sexual dimorphism in wolves (Canis lupus) of the Keewating district Northwest Territories, Canada. Journal of Zoology, 74 (4): 721725, 1996.

13.Frynta, D., Baudysone, J., Hradcova, P., Faltusova, K., Kratochvil, L., Allometry of sexual size dimorphism in domestic dog. PloS ONE 7(9): e 46125, 2012.

14.Morris, J. and Carrier, D., Sexual selection on skeletal shape in Carnivora. Evolution International Journal of Organic Evolution, doi: 10.1111/evo.12904, 2016.

15.Jhala, Y., and Moehlman, P., Golden jackal Canis aureus. Pp. 156-161 in: SilleroZubiri, C., Hoffmann, M., Macdonald, D. eds., Canids: Foxes, Wolves, Jackals and Dogs. Status Survey and Conservation Action Plan IUCN/SSC Canid Specialist Group, Gland \& Cambridge, 2004.

16.Krystufek, B., Murariu, D., Kurtonur, C., Present distribution of the golden jackal Canis aureus in the Balkans and adjacent regions. Mammal Review 27(2):109-114, 1997.

17.Arnold, J., Humer, A., Heltai, M., Murariu, D., Spassov, N., Hacklander, K., Current status and distribution of golden jackals Canis aureus in Europe. Mammal Review, 42: 1- 11, 2012.

18.Boskovic, I., Ozimec, S., Speranda, M., Sprem, N., Degmecic, D., Curovic, M., Spalevic, V., Florijancic, T., Morphometric 
RAICHEV E., et al.

characteristics of the golden jackal populations in Eastern Croatia and Eastern Serbia. Agriculture \& Forestry, Vol. 61, issue 3: 61-68, 2015.

19.Stoyanov, S., Craniometric differentiation of golden jackals (Canis aureus L., 1758) in Bulgaria. International symposium on hunting "Modern aspects of sustainable management of game population" ZemunBelgrade, Serbia, 22 - 24. June, 2012, UDC:639.111.7:305, 2012.

20.Stefanov, P., Physical geography in: Kopralev, I., Yordanova, V. \& Mladenov, Ch., Geography of Bulgaria. ForCom, Sofia, 39-40 pp, 2002. (BG)

21.Peel, M., Finlayson, B., McMachon, T., Updated world map of the Köppen-Geiger climate classification. Hydrology and Earth System Sciences, 11:1633-1644, 2007.

22.Lovich, J. and Gibbons, J., A review of techniques for quantifying sexual size dimorphism. Growth, Development and Aging, 56, 269-281, 1992.
23.Suhomesova, M., Osobennosti bioresursnogo potenciala hishtnih mlekopitaiushtih severnogo makrosklona Centralnogo Kavkaza. DissertaciaAvtoreferat, pp. 29, 2013. (RU)

24.Kononenko, E., Ecological and morphological features of the populations of some dog species (Canidae, Carnivora) in Caucasus. Scientific library of dissertations and synopses of theses dissert., 2011.

25.Quin, D., Smith, A., North, T., Ecogeographic variation in size and sexual dimorphism in sugar gliders and squirrel gliders (Marsupialia: Petauridae). Australian Journal of Zoology, 44:19-45, 1996.

26.Storz, J., Balasingh, J., Bhat, H., Nathan, P., SwamiDoss, D., Prakash, A., Kunz, T., Clinal variation in body size and sexual dimorphism in an Indian fruit bat, Cynopterus sphinx (Chiroptera: Pteropodidae). Biological Journal of the Linnean Society, 72:17-31, 2001. 